\title{
A satisfação com a vida dos egressos de cursos técnicos profissionais em relação ao mercado de trabalho: a perspectiva da Psicologia Positiva
}

The satisfaction with the life of graduates of professional technical courses in relation to the labor market: the perspective Positive Psychology

\section{Rhennan Lazaro de Paulo Lima ${ }^{\dagger *}$, Sílvia Maria Melo Gonçalves*}

Como citar esse artigo. LIMA, R.L.P.; GONÇALVES, S.M.M. A satisfação com a vida dos egressos de cursos técnicos profissionais em relação ao mercado de trabalho: a perspectiva da Psicologia Positiva. Revista Mosaico, v.12, n.1, p. 10-15, 2021

\begin{abstract}
Nota da Editora. Os artigos publicados na Revista Mosaico são de responsabilidade de seus autores. As informações neles contidas, bem como as opiniões emitidas, não representam pontos de vista da Universidade de Vassouras ou de suas Revistas.
\end{abstract}

\author{
Resumo
}

O presente estudo descreve a satisfação com a vida dos egressos dos cursos técnicos integrados, concomitantes e subsequentes, de um instituto federal, no contexto do mercado de trabalho. A compreensão sobre a Qualidade de Vida (QV) envolve domínios que contribuem para o bem-estar das pessoas, como a moradia, os relacionamentos, a saúde, e, nesta abordagem, o trabalho. A discussão sobre QV diz respeito ao posicionamento dos indivíduos diante dos diversos elementos da vida, considerada a partir da percepção de fatores que contribuem com o bem-estar físico, mental e espiritual, pois esses fatores são importantes diante a configuração da vida em sociedade. Participaram desta pesquisa 54 egressos, de ambos os sexos, entre 18 a 50 anos de idade, residentes no município onde se localiza o IF alvo deste estudo e cidades circunvizinhas. O instrumento utilizado foi um questionário misto com 04 perguntas orientadas a explorar como o instituto contribuiu para a inserção dos egressos no mercado de trabalho, o exercício profissional, sua satisfação com o trabalho e para a aplicação de ações empreendedoras. A análise dos dados obtidos com a pesquisa foram categorizadas em frequência simples e percentual, de acordo com a Análise de Conteúdo da Bardin. A pesquisa foi submetida e aprovada por um Comitê de Ética na Pesquisa com Seres Humanos. Diante a abordagem da Educação Técnica Profissional no Brasil, do Mercado de Trabalho e da Psicologia Positiva, tem-se em seus resultados a compreensão da importância da educação profissional e, principalmente, do acesso ao ensino público e de qualidade, conforme percebeu-se pelos resultados apresentados.

Palavras-chave: Satisfação com a vida; Mercado de Trabalho; Psicologia Positiva.

\begin{abstract}
The present study shows the satisfaction with the life of the graduates of the integrated technical courses, concomitant and subsequent, from a federal institute, in the context of the labor market. Understanding Quality of Life (QOL) involves domains that contribute to people's well-being, such as housing, relationships, health, and, in this approach, work. The discussion about QoL involves the positioning of individuals in relation to different elements of life and is considered based on the perception of factors that contribute to physical, mental and spiritual well-being, as these factors are important in view of the configuration of life in society. 54 graduates of both sexes, between 18 and 50 years old, who lived in the municipality where the IF target of this study is located and surrounding cities participated in this research. The instrument used was a mixed questionnaire with 04 questions aimed at exploring how the institute contributed to the insertion of graduates in the labor market, professional practice, their satisfaction with work and the application of entrepreneurial actions. The analysis of the data obtained with the aforementioned research was categorized into simple frequency and percentage, according to Bardin's Content Analysis. The research was submitted and approved by an Ethics Committee on Research with Human Beings. In view of the approach to Professional Technical Education in Brazil, the Labor Market and Positive Psychology, the results show an understanding of the importance of professional education and, mainly, of access to public and quality education, according to the results presented.
\end{abstract}

Keywords: Satisfaction with life; Labor Market; Positive Psychology.

\section{Introdução}

Este artigo teve o objetivo de avaliar a satisfação dos egressos dos cursos técnicos profissionais do IF, no contexto do mercado de trabalho, identificando a contribuição do curso na sua inserção no mercado, na sua prática empreendedora e na sua importância do acompanhamento de egressos.

Sabe-se que o mercado está cada vez mais competitivo, pois, como explica Mariotto (1991, p. 38), a "competitividade" revela que "é desnecessário darmos exemplos da popularidade desse termo [...] já que ela é evidente". Chiavenato $(1999$, p. 01$)$, completa dizendo que "o mundo de hoje é uma sociedade composta por organizações". Deste modo, observa-se que há uma relação de dependência entre as pessoas e as empresas e a formação acadêmica representa mais chances na busca por um emprego.

O instituto alvo deste estudo foi implantado em 2014, ofertando os Cursos Técnicos na Modalidade Concomitante/Subsequente e Cursos Integrados ao Ensino Médio. Refletindo sobre as atividades desenvolvidas nesta instituição, surgiram as seguintes indagações: qual a satisfação dos egressos quanto a sua inserção no mercado de trabalho? e como a instituição contribuiu para seu bem-estar subjetivo em relação à satisfação com a vida? As indagações apresentadas surgiram e foram motivadas durante a organização dos Encontros de Egressos realizados na instituição.

Para alçar os resultados, o trabalho se fundamentou analiticamente nos aspectos históricos da Rede Federal de Educação, com destaque ao campus pesquisado, nos estudos sobre o Mercado de Trabalho e suas ramificações

Afiliação dos autores:

† Mestre em Educação pela Universidade Federal Rural do Rio de Janeiro (UFRRJ), Seropédica, RJ, Brasil.

¿ Doutora em Psicologia; Professora Titular da Universidade Federal Rural do Rio de Janeiro (UFRRJ), Seropédica, RJ, Brasil.

Trabalho baseado na dissertação de Mestrado em Educação, apresentado ao Programa de Pós-graduação em Educação Agrícola, da Universidade Federal Rural do Rio de Janeiro.

* Email de correspondência: rhennan.1@gmail.com 
e na Psicologia Positiva, que nos permitiram obter os resultados que são apresentados neste artigo.

\section{Rede Federal de Educação}

O Sistema Federal de Ensino é formado pela Lei $\mathrm{N}^{\mathrm{o}} 11.892$, de 29 de dezembro de 2008, composto pela Universidade Tecnológica Federal do Paraná; pelo Centro Federal de Educação Tecnológica de Minas Gerais e do Rio de Janeiro; pelas Escolas Técnicas Vinculadas às Universidades Federais e pelo Instituto Federal de Educação, Ciência e Tecnologia.

Numa perspectiva diacrônica, em 1909, surgiram as Escolas de Aprendizes Artífices (EAA). O art. $1^{\circ}$ do Decreto de criação das EAA (Decreto $\mathrm{N}^{\circ}$ 7.566, de 23 de setembro de 1909) dizia que cada uma das capitais dos Estados da República deveria manter uma Escola de Aprendizes Artífices destinada ao ensino profissional. Em 1937, por meio da Lei No 378, de 13 de janeiro de 1937, as EAA foram transformadas em Liceus Industriais, que, em 1942, passaram a se chamar Escolas Industriais e Técnicas. O art. $3^{\circ}$ da Lei Orgânica do Ensino Industrial (Lei $\mathrm{N}^{\circ} 4.073$, de 30 de janeiro de 1942) destacava que o ensino deveria atender aos interesses do trabalhador, isto é, preparando-o para o mercado de trabalho.

Com mais autonomia, em 1959, o ensino técnico ganhou mais destaque. A alínea "a" do art. $1^{\circ}$ da Lei $\mathrm{N}^{\circ}$ 3.552, de 16 de fevereiro de 1959, disciplina in verbis, "proporcionar base de cultura geral e iniciação técnica que permitam ao educando integrar-se na comunidade e participar do trabalho produtivo ou prosseguir seus estudos". Pelo excerto, percebe-se as mudanças administrativas e políticas quanto ao gerenciamento do ensino técnico no Brasil. Nessa evolução, em 1978, surgiram os Centros Federais de Educação Tecnológica (CEFET) e, seguidamente, por intermédio da Lei $\mathrm{N}^{\mathrm{o}} 11.982$, de 29 de dezembro de 2008, surgiram os Institutos Federais (IF). $\mathrm{O}$ art. $2^{\circ}$ da lei supracitada destaca que:

Os Institutos Federais são instituições de educação superior, básica e profissional, pluricurriculares e multicampi, especializados na oferta de educação profissional e tecnológica nas diferentes modalidades de ensino, com base na conjugação de conhecimentos técnicos e tecnológicos com as suas práticas pedagógicas [...] (BRASIL, 2008).

São 38 Institutos Federais espalhados pelo Brasil, vinculados ao Ministério da Educação. Em especial, o instituto federal alvo deste estudo, com 12 campi, está presente nas cidades de Iporá, Trindade, Campos Belos, Rio Verde, Morrinhos, Ceres, Urutaí, Posse, Catalão, Hidrolândia, Cristalina e Ipameri, no Estado de Goiás.

O campus do IF pesquisado oferta cursos de Formação Inicial e Continuada (FIC), Cursos Técnicos,
Cursos Superiores e Pós-graduações. Neste sentido, Mendes $(2010$, p. 68) "A educação é de fundamental importância para que os indivíduos tenham capacidade de compreender o contexto social em que estão inseridos e possam responder à altura aos desafios enfrentados pela sociedade". Nesse sentindo, as atividades de Ensino, Pesquisa e Extensão são fundamentais para a formação do discente.

\section{Mercado de Trabalho}

As organizações se desenvolveram ao longo do tempo, contribuindo com o processo evolutivo, suprindo as demandas e criando produtos e/ou serviços necessários para a sociedade, que, naturalmente, tem suas necessidades em constantes mudanças. De acordo com Caravantes e Bjur (1996, p. 25), "no mercado global de hoje, consumidores de qualquer continente podem ter acesso às opções de compra de artigos produzidos em qualquer um dos vários outros continentes". Nesta afirmação, compreende-se que com a globalização houve a possibilidade do estreitamento nas relações comerciais.

As organizações avançaram no tempo, como destaca Hall (2004, p. 16) ao justificar que "as organizações são participantes ativas na sociedade"; desta forma, sua evolução acompanha as transformações do mundo. Uma organização é formada por um conjunto composto de recursos: financeiros, humanos e materiais, que devem ser coordenados para que as suas sinergias gerem resultados.

Esse gerenciamento se dá por um profissional, o administrador, que deve ter/desenvolver habilidades para o exercício de sua função. De acordo com Robert (1955 apud CHIAVENATO, 1999, p. 2), o administrador deve apresentar três habilidades, que devem ser aplicadas dentro da empresa, quais sejam: as habilidades técnicas, as humanas e as conceituais, que são indispensáveis no exercício de sua função, uma vez que envolvem todos os pontos relacionados com a atividade profissional.

Destacam-se as habilidades humanas, pois as empresas são compostas por pessoas que fornecem seu tempo, energia e experiência ao empregador em troca de salário e crescimento profissional. Segundo Etzioni (1965, p. 690-991 apud HALL, 2004, p. 127) "liderança é uma forma especial de poder, intimamente relacionada à forma 'referencial' [...], pois envolve a habilidade, baseada nas qualidades pessoais do líder [...]”. Em uma organização, tal habilidade é fundamental para que a sinergia dos elementos mencionados.

A compreensão sobre o "Mercado de Trabalho" pode ser entendida de formas múltiplas. Com isso, analisar o mercado e desenvolver as habilidades profissionais são exemplos de ações a serem elaborados para aumentar as chances de obter um emprego e, claro, 
novas posições na organização. Segundo Oliveira e Piccinini (2011, p. 1532) "[...] o mercado de trabalho pode ser entendido como um espaço de lutas entre diferentes agentes (indivíduos, organizações, órgãos de regulação, países etc.) [...]". A expressão "luta" significa os interesses, que não raras vezes são conflitantes entre esses agentes e refletem na empregabilidade.

Lavinas (2001, p. 3 apud HELOL; ROCHA, 2011, p. 140) define o termo empregabilidade como "as características individuais do trabalhador capazes de fazer com que possa escapar do desemprego mantendo sua capacidade de obter um emprego", ou seja, o trabalhador precisa desenvolver suas habilidades para obter uma vaga no mercado de trabalho. Para Oliveira e Piccinini (2011, p. 1527): “[...] a compreensão do mercado de trabalho, destaca-se a importância da atuação de diferentes atores (sindicatos, governo, empresas etc.) [...]", pois, são responsáveis pelo regramento do trabalho.

Em uma sociedade moderna, a compreensão sobre o trabalho é manifestada pelo exercício do homem em busca de sobrevivência. De acordo com Murad (2017, p. 94), "em um mercado altamente competitivo, no qual a qualificação e a boa formação profissional tornou-se um requisito aos indivíduos [...], para fazerem parte do novo mundo do trabalho [...]". Para encontrar um trabalho nesse mercado competitivo, a qualificação profissional se torna um requisito indispensável.

\section{Psicologia Positiva: a satisfação com a vida}

A Psicologia Positiva é uma nova corrente dentro da ciência psicológica que envolve o estudo sobre o quanto as pessoas podem ser mais felizes e satisfeitas. Diariamente são divulgadas nos veículos de comunicação muitas notícias tristes que ocorrem no mundo, como a guerra, a criminalidade, as doenças, entre outras, que vão na contramão da percepção de felicidade e satisfação com a vida, sendo causadoras de doenças, como a depressão e o medo.

Essa nova abordagem psicológica surgiu em 1998, quando a Psicologia trouxe questões inerentes às causas da felicidade por meio da Psicologia Positiva, que teve início quando o psicólogo Martin Seligman assumiu a presidência da American Psychological Association (PALUDO; KOLLER, 2007, p. 10). Como presidente desta associação, Seligman propôs um novo campo de estudo, ao invés de uma ciência curativa para a construção da qualidade de vida (GONÇALVES, 2006, p. 15).

Neste adendo, Scorsolini-Comin (2012) destacou em seu trabalho uma indagação feita pelo professor Martin E. P. Seligman a respeito da abordagem feita até então pela psicologia sobre as doenças e os aspectos disfuncionais, não abordando os aspectos positivos do desenvolvimento. Nesta acepção, a Psicologia vai além de curar patologias, pois com a Psicologia Positiva se pôde melhorar a qualidade de vida das pessoas, diante a compreensão dos aspectos positivos da vida.

De acordo com Gonçalves (2006, p. 22), "o termo 'qualidade'é indefinido e bastante complexo e, devido a sua natureza abstrata, o conceito de 'qualidade de vida' vem sendo empregado na literatura com designações bem divergentes [...]". Neste sentido, a Qualidade de Vida (QV) envolve o posicionamento dos indivíduos diante a diversos elementos da vida humana e contribuem com o seu bem-estar físico, mental e espiritual.

Segundo Pereira, Teixeira e Santos (2012, p. 241), "a qualidade de vida vem de um movimento [...] no sentido de valorizar parâmetros mais amplos que o controle de sintomas, a diminuição da mortalidade ou o aumento da expectativa de vida". Em uma sociedade heterogênea, com grandes diferenças sociais, o estudo sobre a QV representa a atenção quanto a questões econômicas e sociais da sociedade. Segundo Giacomoni (2004, p. 43):

Diferentes abordagens vêm investigando a qualidade de vida das pessoas ao longo do tempo. A Economia avalia a qualidade de vida das sociedades através da quantidade de bens, mercadorias e serviços que são produzidos pelas comunidades. Já os cientistas sociais adicionam à avaliação objetiva da Economia indicadores sociais importantes como: baixas taxas de crime, expectativa de vida, respeito pelos direitos humanos e distribuição equitativa dos recursos. Uma terceira abordagem de definição e avaliação da qualidade de vida é o bem-estar subjetivo (GIACOMONI, 2004, p. 43).

A abordagem adotada dentro da Psicologia Positiva para a Qualidade de Vida é o Bem-estar Subjetivo. Gonçalves (2006, p. 24) revela que "a satisfação é um subcomponente do bem-estar subjetivo e não pode ser considerado como felicidade". Cada um desses termos - felicidade e satisfação - apresentam posicionamentos próprios.

Os precursores dessa corrente, Seligman (2009) e Csikszentmihalyi (1999) fizeram uma análise entre 1970 e 2006, da qual observaram que haviam poucos trabalhos científicos que tratavam sobre "Felicidade" (4.711) em comparação com os trabalhos sobre "Depressão" (110.382) publicados na PsycInfo, um banco de dados em pesquisas que se referem a Psicologia. Desta forma, ambos os autores publicaram um trabalho que fazia uma crítica a Psicologia e a importância de uma abordagem científica sobre os aspectos positivos da vida humana, como a esperança, a criatividade, a coragem, a felicidade, entre outros (PALUDO; KOLLER, 2007, p. 10).

De acordo com Czikszentmihalyi (1999, p. 26), "não queremos realmente a riqueza, ou saúde, ou a fama por si sós - queremos essas coisas porque esperamos que elas nos tornem felizes". Desta forma, compreendese que as pessoas querem ser felizes e satisfeitas com 
suas vidas. Seligman (2009, p. 58) destacou que "os sentimentos positivos em relação a uma pessoa ou objeto provocam aproximação, enquanto sentimentos negativos provocam afastamento". Com isso, os subcomponentes do bem-estar subjetivo representam a essência para uma vida melhor.

Albuquerque e Tróccoli (2004, p. 153) afirmam que "o estudo do Bem-Estar Subjetivo (BES) busca compreender a avaliação que as pessoas fazem de suas vidas", dos elementos em que as pessoas estão expostas, as fazem perceber e/ou medir sua qualidade de vida. Como um subcomponente da QV, a BES envolve questões ligadas à emoção, ou melhor, a avaliação feita dos fatores que venham a contribuir com essa percepção pelo exposto aos domínios da satisfação com a vida.

Segundo Gonçalves (2006, p. 25), "a satisfação de vida é representada pelo auto-relato de como a pessoa percebe a sua vida em relação ao presente, ao passado e às expectativas em relação ao futuro, em vários domínios", em especial o domínio "trabalho", uma vez representa peso crucial nesta percepção, pois grande parte da vida humana é destinada ao exercício de atividades em prol da manutenção da vida, que segundo Cotrim (1993, p. 152), "é o instrumento de progresso social e realização individual", ou seja, o trabalho representa sobrevivência e crescimento pessoal e profissional, além de representar o fortalecimento da economia do país.

\section{Métodos}

O método utilizado foi o da pesquisa qualitativa e exploratória. Segundo Martins (2004, p. 292), “a variedade de material obtido qualitativamente exige do pesquisador uma capacidade integrativa e analítica que, por sua vez, depende do desenvolvimento de uma capacidade criadora e intuitiva". Desta forma, a dedicação para esta pesquisa se refletiu na seriedade e nos objetivos alcançados.

Participaram da pesquisa 54 egressos. O instrumento utilizado para coleta de dados foi o questionário misto e a análise dos dados foi categorizada em frequência simples e percentual, de acordo com a Análise de Conteúdo da Bardin (2011, p. 131). A pesquisa foi realizada em três etapas: $1^{\circ}$ Pré-Teste; $2^{\circ}$ Encontro de Egressos; e $3^{\circ}$ Pesquisa a Campo.

A presente pesquisa foi submetida ao Comitê de Ética na Pesquisa com Seres Humanos da UFRRJ, por meio do Processo $N^{\circ}$ 23083.024555/2019-98, e aprovado por meio do Despacho $\mathrm{N}^{\circ}$ 18644. Os participantes assinaram o Termo de Consentimento Livre e Esclarecido, respeitando todos os princípios éticos para pesquisas com seres humanos.

\section{Resultados e discussão}

Os resultados das respostas encontradas na questão $\mathrm{n}^{\circ}$ 01, "Por que você escolheu um curso Técnico no IF?", totalizam 54 respostas, que foram categorizadas, conforme observado na Tabela 1, em Frequências Simples e Percentuais, onde podemos identificar o posicionamento dos egressos.

Tabela 1. Frequências e Percentuais das Categorias da Questão n ${ }^{\circ}$ 01 .

\begin{tabular}{c|c|c} 
Categorias & $\begin{array}{c}\text { Frequência } \\
\text { Simples }\end{array}$ & $\begin{array}{c}\text { Frequência } \\
\text { Percentual }\end{array}$ \\
\hline Qualidade da instituição e/ou curso & 25 & 37,88 \\
\hline Melhorar o currículo & 16 & 24,24 \\
\hline Aprendizagem & 16 & 24,24 \\
\hline Ensino Público e Gratuito & 3 & 4,55 \\
\hline Horário do curso/local & 3 & 4,55 \\
\hline Indicação de amigos & 2 & 3,03 \\
\hline Duração do curso & 1 & 1,52 \\
\hline Total & $\mathbf{6 6}$ & $\mathbf{1 0 0 ,}$
\end{tabular}

As respostas apontaram que $37,88 \%(\mathrm{f}=25)$ dos participantes levaram em consideração a qualidade da instituição de ensino ofertado na escolha de um curso neste campus avançado. De acordo com Mendes (2010, p. 69), "[...] a educação passa a ser um ato de intervenção no mundo, e, para que haja intervenção, é necessária uma prática docente formadora, compromissada, correta, ética, de forma que seja realmente humana". Desta forma, identificamos que é uma preocupação do discente uma educação de qualidade. Dentre os participantes, $24,24 \%(\mathrm{f}=16)$ visaram a construção de um currículo mais competitivo, pois identificaram que o curso contribuiria com a melhoria do seu currículo e, consequentemente, the daria mais chances no mercado de trabalho.

Quanto à aprendizagem, 24,24\% $\quad(\mathrm{f}=16)$ responderam que entraram no IF para aumentar seus conhecimentos; $4,55 \%(\mathrm{f}=3)$ destacaram que a escolha pelo curso/campus foi pelo ensino público; $4,55 \%$ ( $\mathrm{f}=3$ ) registraram que o horário de oferta do curso foi levado consideração; $3,03 \%(\mathrm{f}=2)$ destacaram que vieram para a instituição por indicação de amigos; e 1,52\% (f=1) por conta da duração do curso.

A questão $\mathrm{n}^{\circ}$ 02, "O IF contribuiu com sua inserção no mercado de trabalho?", obteve 49 respostas, que foram categorizadas em Frequências Simples e Percentuais, de acordo com a Tabela 2.

Para esta pergunta, 57,41\% ( $\mathrm{f}=31)$ responderam que sim, demostrando aspectos positivos quando à visão de mercado e sobre a certificação oriunda da 
instituição. Mas 33,33\% ( $\mathrm{f}=18$ ) responderam que não e $9,26 \%(f=5)$ não responderam. Oliveira e Piccinini (2011, p. 1518) destacam que o Mercado de Trabalho vem sofrendo grandes transformações tecnológicas e que compreender esse mercado é um grande desafio.

A questão $\mathrm{n}^{\mathrm{o}}$ 03, "Quais as dificuldades encontradas após o término do curso?", obteve 51 respostas, que foram categorizadas em Frequências Simples e Percentuais e constam na tabela 3.

Tabela 2. Frequências e Percentuais das Categorias da Questão $n^{\circ}$ 02 .

\begin{tabular}{c|c|c} 
Categorias & $\begin{array}{c}\text { Frequência } \\
\text { Simples }\end{array}$ & $\begin{array}{c}\text { Frequência } \\
\text { Percentual }\end{array}$ \\
\hline Sim & 31 & 57,41 \\
\hline Não & 18 & 33,33 \\
\hline Não Respondeu & 5 & 9,26 \\
\hline Total & $\mathbf{5 4}$ & $\mathbf{1 0 0}$,
\end{tabular}

Tabela 3. Frequências e Percentuais das Categorias da Questão ${ }^{\circ}$ 03.

\begin{tabular}{c|c|c} 
Categorias & $\begin{array}{c}\text { Frequência } \\
\text { Simples }\end{array}$ & $\begin{array}{c}\text { Frequência } \\
\text { Percentual }\end{array}$ \\
\hline Falta de oportunidades & 33 & 53,23 \\
\hline Não apresentou dificuldades & 8 & 12,90 \\
\hline Falta de Experiência & 7 & 11,29 \\
\hline Ingresso no ensino superior & 7 & 11,29 \\
\hline Salários baixos & 1 & 1,61 \\
\hline Concorrência do mercado & 1 & 1,61 \\
\hline Desemprego & 1 & 1,61 \\
\hline Falta de concurso na área de formação & 1 & 1,61 \\
\hline Não respondeu & 3 & 4,84 \\
\hline Total & $\mathbf{6 2}$ & $\mathbf{1 0 0 ,}$
\end{tabular}

Quanto às dificuldades encontradas após o término do curso técnico no IF, 53,23\% $(\mathrm{f}=33)$ dos participantes identificaram que a principal dificuldade foi a falta de oportunidade oferecida pelo mercado de trabalho, enquanto $12,90 \%(\mathrm{f}=8)$ responderam que não encontraram dificuldades.

A falta de experiências profissionais foi apontada por $11,29 \%(f=7)$; outros $11,29 \%(f=7)$ responderam sobre o apuro do ingresso no ensino superior; $1,61 \%$ $(\mathrm{f}=1)$ mencionaram baixos salários; $1,61 \% \quad(\mathrm{f}=1)$ responderam que a concorrência do mercado de trabalho foi a maior dificuldade que encontraram; $1,61 \%(\mathrm{f}=1)$ apontaram para o desemprego; $1,61 \%(\mathrm{f}=1)$ registraram falta de concursos para sua área de formação; e apenas $4,84 \%(\mathrm{f}=3)$ não responderam esta pergunta. Silveira et al. (2015, p. 273) destacam que a satisfação com a vida envolve domínios como saúde, trabalho, moradia, autonomia, entre outros; com isso, diante o exposto com os resultados obtidos nesta pergunta, podemos destacar que encontrar um trabalho ainda é um desafio que, consequentemente, compromete a satisfação com a vida.

As respostas dos participantes para a questão $\mathrm{n}^{\circ} 4$, "Você desenvolve alguma atividade autônoma ou pensa em se tornar o dono do seu próprio negócio?", obteve 54 respostas que foram categorizadas em Frequências Simples e Percentuais na Tabela 4.

Tabela 4. Frequências e Percentuais das Categorias da Questão ${ }^{\circ}$ 04.

\begin{tabular}{c|c|c} 
Categorias & $\begin{array}{c}\text { Frequência } \\
\text { Simples }\end{array}$ & $\begin{array}{c}\text { Frequência } \\
\text { Percentual }\end{array}$ \\
\hline Quer ter seu próprio negócio & 26 & 48,15 \\
\hline Não pensa em ter seu próprio negócio & 19 & 35,19 \\
\hline Atuante como autônomo & 9 & 16,67 \\
\hline Total & $\mathbf{5 4}$ & $\mathbf{1 0 0}$,
\end{tabular}

Dentre os participantes, $48,15 \% \quad(\mathrm{f}=26)$ responderam que pensam em ser donos do próprio negócio; 35,19\% ( $\mathrm{f}=19)$ responderam que não pensam em ter sua empresa; e $16,67 \%(\mathrm{f}=9)$ são profissionais autônomos.

\section{Considerações Finais}

A execução desta pesquisa denota a importância do acompanhamento dos egressos e a importância da instituição de ensino no aprendizado e certificação e na carreira profissional de seus discentes, pois em um mercado competitivo a formação técnica profissional dá aos egressos mais chances de encontrarem um emprego e de se manterem empregados. Observa-se também que a iniciativa de um negócio próprio é impulsionada diante da compreensão do mercado de trabalho.

Neste estudo, conclui-se que participantes levaram em consideração a qualidade do curso no momento do ingresso na instituição e que o IF desenvolve um excelente trabalho, refletido na satisfação com a vida dos egressos dos cursos técnicos sob o domínio do trabalho e, ainda, com o cumprimento da missão do IF que é "[...] promover educação profissional e tecnológica de excelência, visando à formação integral e emancipatória 
do cidadão para o desenvolvimento da sociedade".

\section{Referências}

ALBUQUERQUE, Anelise Salazar; TRÓCCOLI, Bartholomeu Tôrres. Desenvolvimento de Uma Escala de Bem-Estar Subjetivo. Psic.: Teor. e Pesq., Brasília, v. 20 n. 2, p. 153-164, maio/ago. 2004. Disponível em: http:// www.scielo.br/pdf/ptp/v20n2/a08v20n2.pdf. Acesso em 12 jun. 2018.

BARDIN, Laurence. Análise de Conteúdo. Tradução de Luís Antero Reto e Augusto Pinheiro. São Paulo: Edições 70, 2011.

BRASIL. Decreto Nº 7.566, de 23 de setembro de 1909. Cria as Escolas de Aprendizes Artífices. Rio de Janeiro, 1909. Disponível em: http://www2. camara.leg.br/legin/fed/decret/1900-1909/decreto-7566-23-setembro-1909525411-publicacaooriginal-1-pe.html. Acesso em: 22 out. 2018.

BRASIL. Lei n. 11.892, de 29 de dezembro de 2008. Institui a Rede Federal de Educação Profissional, Científica e Tecnológica, cria os Institutos Federais de Educação, Ciência e Tecnologia, e dá outras providências. Brasília, Presidência da República, 2008.

BRASIL. Lei $\mathbf{N}^{0} \mathbf{3 7 8}$, de 13 de janeiro de 1937. Dá nova organização ao Ministério da educação e Saúde Pública. Rio de Janeiro, 1937. Disponível em: http://www2.camara.leg.br/legin/fed/lei/1930-1939/lei-378-13-janeiro1937-398059-publicacaooriginal-1-pl.html. Acesso em: 22 out. 2018

BRASIL. Lei $\mathrm{N}^{\circ} \mathbf{3 . 5 5 2}$, de 16 de fevereiro de 1959. Dispõe sobre nova organização escolar e administrativa dos estabelecimentos de ensino industrial do Ministério da Educação e Cultura, e dá outras providências. Rio de Janeiro, 1959. Disponível em: http:/www.planalto.gov.br/ccivil_03/ LEIS/L3552.htm. Acesso em: 24 out. 2018.

BRASIL. Lei $\mathbf{N}^{\mathbf{0}} \mathbf{4 . 0 7 3}$, de 30 de janeiro de 1942. Lei Orgânica do Ensino Industrial. Rio de Janeiro, 1942. Disponível em: https://www.planalto.gov. br/ccivil 03/decreto-lei/1937-1946/Del4073.htm. Acesso em: 24 out. 2018.

CARAVANTES, Geraldo; BJUR, Wesley. ReAdministração em Ação. São Paulo: Makron Books, 1996.

CHIAVENATO, Idalberto. Introdução à Teoria Geral da Administração. São Paulo: Makron Books, 1999.

CSIKSZENTMIHALYI, Mihaly. A Descoberta do Fluxo: a psicologia do envolvimento com a vida cotidiana. Rio de Janeiro: Rocco, 1999.

COTRIM, Gilberto. Direito do Trabalho: introdução ao Direito. São Paulo: Saraiva, 1993.

GIACOMONI, Claudia Hofheinz. Bem-estar Subjetivo: em busca da qualidade de vida. Temas em Psicologia da SBP, Santa Maria, v. 12, n. 1, p. 43-50, 2004. Disponível em: http://pepsic.bvsalud.org/pdf/tp/v12n1/ v12n1a05.pdf. Acesso em: 20 out 2018.

GONCALVES, Sílvia Maria Melo. Mas, afinal, o que é felicidade? Ou, quão importantes são as relações interpessoais na concepção de felicidade entre adolescente. 222f. 2006. Tese. Universidade Federal do Rio de Janeiro, Rio de Janeiro, 2006.

HALL, Richard. Organizações: estruturas, processos e resultados. São Paulo: Prentice Hall, 2004.

HELOL, Diogo Henrique; ROCHA, Maíra. O discurso da empregabilidade: o que pensam a academia e o mundo empresarial. Cadernos Ebape, Rio de Janeiro, v. 9, n. 1, artigo 8, mar. 2011. Disponível em: http://www.scielo.br/ pdf/cebape/v9n1/v9n1a09.pdf. Acesso em: 30 nov. 2019.

MARIOTTO, Fábio. O Conceito de Competitividade da Empresa: uma análise crítica. Revista de Administração de Empresas, São Paulo, v. 31, n. 2, p. 37-52, 1991.

MARTINS, Heloisa Helena T. de Souza. Metodologia Qualitativa de Pesquisa. Educação e Pesquisa, São Paulo, v. 30, n. 2, p. 289-300, maio/ ago. 2004. Disponível em: https://www.scielo.br/pdf/ep/v30n2/v30n2a07. pdf. Acesso em: 06 ago. 2020.

MENDES, Maria Socorro dos Santos. Qualidade de Ensino na Escola Pública: desafios e (im)possibilidades. Psicologia: ensino e formação, Perdizes, v. 1, n. 2, p. 61-71, 2010. Disponível em: http://pepsic.bvsalud.org/pdf/pef/v1n2/ v1n2a06.pdf. Acesso em: 30 mar 2020.

MURAD, Isabela. O Mercado de Trabalho na Área de Administração: analisando a formação e as demandas das organizações. Revista Foco, Vila Velha, v. 10, n. 2, p. 82-97, jan./jul. 2017.

OLIVEIRA, Sidinei Rocha de; PICCININI, Valmiria Carolina. Mercado de Trabalho: múltiplos (des)entendimentos. Revista Adm. Pública, Rio de Janeiro, v. 45, n. 5, 2011 .

PALUDO, Simone dos Santos; KOLLER, Sílvia Helena. Psicologia Positiva: uma nova abordagem para antigas questões. Paidéia, Ribeirão Preto, v. 17, n. 36 , p. $9-20,2007$.

PDI. Plano de Desenvolvimento Institucional do Instituto Federal Goiano. 2019/2023. Disponível em: https://suap.ifgoiano.edu.br/media/ documentos/arquivos/39 - PDI 2019-2023 - revisado 18-03-2019.pdf. Acesso em: 20 jul. 2020.

PEREIRA, Érico Felden; TEIXEIRA, Clarissa Stefani; SANTOS, Anderlei. Qualidade de Vida: abordagens, conceitos e avaliação. Rev. bras. Educ. Fís. Esporte, São Paulo, v. 26, n. 2, p. 241-50, abr./jun. 2012.

SCORSOLINI-COMIN, F. Por uma Nova Compreensão do Conceito de Bem-estar: Martin Seligman e a Psicologia Positiva. Padéia, Ribeirão Preto, v. 22, n. 53, p. 433-435, set./dez. 2012. Disponível em: http://www.scielo.br/ pdf/paideia/v22n53/15.pdf. Acesso em: 11 jun. 2018.

SELIGMAN, Martin E. P. Felicidade Autêntica: usando a psicologia positiva para a realização permanente. Tradução de Neuza Capelo. Rio de Janeiro: Objetiva, 2009.

SILVEIRA, Pablo Magno da; BORGATTO, Adriano Ferreti; SILVA, Kelly Samara da; OLIVEIRA, Elusa Santina Antunes de; BARROS, Mauro Virgílio Gomes de; NAHAS, Markus Vinicius. Criação de uma escala de satisfação com a vida por meio da Teoria da Resposta ao Item. J Bras Psiquiatr, Rio de Janeiro, v. 64, n. 4, p. 272-278, 2015. 